\title{
SEX RATIO AND THE ABO BLOOD GROUP SYSTEM
}

\author{
BY
}

\author{
J. M. JOHNSTONE
}

From the Department of Pathology, the University and Western Infirmary, Glasgow

An interesting association between the sex ratio at birth and the ABO blood group system has been demonstrated by Sanghvi (1951). He showed, in each of two population samples, one from New York and the other from Bombay, that the sex ratio (percentage of males) of Group O infants of Group $\mathbf{O}$ mothers was significantly higher than that of Group A infants of Group A mothers; the ratio for Group B infants of Group B mothers approximated closely with the first ratio. Allan $(1952 \mathrm{a} ; 1952 \mathrm{~b}$; 1953) further analysed Sanghvi's material and also attempted to correlate the sex ratio data with certain fertility data of various mating types compiled by Waterhouse and Hogben (1947).

This paper reports a similar analysis of an English population sample drawn from the West London and West Middlesex area.

\section{MATERIAL}

Throughout the year 1950, ABO and Rh blood group determinations were made by the tube techniques (M.R.C. Memoranda Nos. 9 and 19) on all mothers delivered in the maternity department of the West Middlesex Hospital, Isleworth, their infants, and as many of the fathers as was possible.

\section{ANALYSIS}

The number of infants of each $\mathrm{ABO}$ group born to mothers of each group are detailed in Table $I$, the overall sex ratio is $51 \cdot 9 \pm 1 \cdot 0$.

The sex ratio, irrespective of the mother's group, for all Group B infants is $54 \cdot 4 \pm 3 \cdot 3$, for all Group $O$ infants $52 \cdot 1 \pm 1 \cdot 5$, and for all Group $A$ infants $51 \cdot 5 \pm 1 \cdot 6$. The sex ratio of all infants born of Group B mothers is $55 \cdot 1 \pm 3 \cdot 5$, of Group $O$ mothers $52 \cdot 0 \pm 1 \cdot 5$, and of Group A mothers $51 \cdot 3 \pm 1 \cdot 5$. Lastly, the sex ratio of Group B infants of Group B mothers $(54 \cdot 3 \pm 5 \cdot 5)$ exceeds both that of Groun $\mathrm{O}$ infants of Group $\mathrm{O}$ mothers
TABLE I

NUMBERS AND ABO BLOOD GROUPS OF INFANTS BORN TO MOTHERS OF EACH BLOOD GROUP

\begin{tabular}{|c|c|c|c|c|c|c|c|}
\hline \multicolumn{2}{|c|}{ Infants } & \multicolumn{4}{|c|}{ Mothers } & \multicolumn{2}{|c|}{ Total Infants } \\
\hline Group & Sex & O & $\mathbf{A}$ & B & AB & No. & per cent. male \\
\hline \multirow{2}{*}{$\mathbf{O}$} & Male & 385 & 145 & 41 & - & 571 & \multirow{2}{*}{$52 \cdot 1 \pm 1 \cdot 0$} \\
\hline & Female & 371 & 126 & 29 & - & 526 & \\
\hline \multirow{2}{*}{$\mathbf{A}$} & Male & 149 & 345 & 11 & 21 & 526 & \multirow{2}{*}{$51 \cdot 5 \pm 1 \cdot 6$} \\
\hline & Female & 126 & 346 & 9 & 14 & 495 & \\
\hline \multirow{2}{*}{ B } & Male & 39 & 29 & 44 & 13 & 125 & \multirow{2}{*}{$54 \cdot 4 \pm 3 \cdot 3$} \\
\hline & Female & 33 & 18 & 37 & 17 & 105 & \\
\hline \multirow{2}{*}{$\mathbf{A B}$} & Male & - & 16 & 18 & 5 & 39 & \multirow{2}{*}{$48 \cdot 1 \pm 5 \cdot 6$} \\
\hline & Female & - & 18 & 18 & 6 & 42 & \\
\hline \multirow{2}{*}{ Total } & Male & 573 & 535 & 114 & 39 & 1,261 & \multirow{2}{*}{$51 \cdot 9 \pm 1 \cdot 0$} \\
\hline & Female & 530 & 508 & 93 & 37 & 1,168 & \\
\hline
\end{tabular}

$(50.9 \pm 1.8)$ and that of Group A infants of Group A mothers (49.9 $\pm 1 \cdot 9)$. None of the differences between the ratios in this analysis is significant, but the descending sex ratio order is $\mathrm{B}-\mathrm{O}-\mathrm{A}$. Apart from the high sex ratio for Group B infants of Group B mothers these findings do not confirm those of Sanghvi (1951).

The number of fathers in each group, and their children, who were available for analysis in this sample is shown in Table II (opposite).

The overall sex ratio is $51 \cdot 8 \pm 1 \cdot 0$. The sex ratio for all Group $O$ infants, irrespective of the father's group, is $52 \cdot 5 \pm 1 \cdot 6$, for Group A infants $51 \cdot 4 \pm 1 \cdot 7$, and for Group B infants $51 \cdot 5 \pm 3 \cdot 6$; for all infants born of Group $O$ fathers the ratio is $52 \cdot 2 \pm 1 \cdot 6$, of Group $A$ fathers $51 \cdot 5 \pm 1 \cdot 6$, and of Group B fathers $49 \cdot 0 \pm 3 \cdot 4$. The sex ratio of Group $O$ infants born of Group $O$ fathers is $52.9 \pm 1.9$, of Group A infants of Group A fathers $51 \cdot 7 \pm 2 \cdot 0$, and of Group B infants of Group B fathers $48 \cdot 9 \pm 5 \cdot 2$. Again none of the differences between the ratios in the analysis is significant but here the descending sex ratio order is $\mathrm{O}-\mathrm{A}-\mathrm{B}$. 
TABLE II

NUMBERS AND ABO BLOOD GROUPS OF INFANTS BORN TO FATHERS OF EACH BLOOD GROUP

\begin{tabular}{|c|c|c|c|c|c|c|c|}
\hline \multicolumn{2}{|c|}{ Infants } & \multicolumn{4}{|c|}{ Fathers } & \multicolumn{2}{|c|}{ Total Infants } \\
\hline Group & Sex & O & $\mathbf{A}$ & B & $\mathbf{A B}$ & No. & per cent. mae \\
\hline \multirow{2}{*}{ o } & Male & 333 & 140 & 36 & - & 509 & \multirow{2}{*}{$52 \cdot 5 \pm 1 \cdot 16$} \\
\hline & Female & 297 & 127 & 37 & - & 461 & \\
\hline \multirow{2}{*}{$\mathbf{A}$} & Male & 129 & 313 & 8 & 13 & 463 & \multirow{2}{*}{$51.4 \pm 1 \cdot 7$} \\
\hline & Female & 121 & 293 & 9 & 14 & 437 & \\
\hline \multirow{2}{*}{ B } & Male & 24 & 9 & 45 & 23 & 101 & \multirow{2}{*}{$51 \cdot 5 \pm 3 \cdot 6$} \\
\hline & Female & 28 & 12 & 47 & 8 & 95 & \\
\hline \multirow{2}{*}{$\mathbf{A B}$} & Male & - & 17 & 14 & 6 & 37 & \multirow{2}{*}{$49 \cdot 3 \pm 5 \cdot 8$} \\
\hline & Female & 一 & 20 & 14 & 4 & 38 & \\
\hline \multirow{2}{*}{ Total } & Male & 486 & 479 & 103 & 42 & 1,110 & \multirow{2}{*}{$51 \cdot 8 \pm 1 \cdot 0$} \\
\hline & Female & 446 & 452 & 107 & 26 & 1,031 & \\
\hline
\end{tabular}

In this population sample, therefore, all that may be said at this point is that children of Group B mothers tend to have a high sex ratio, while those of Group B fathers are associated with a low sex ratio. This may be further examined by the determination of the sex ratios of children born to the various ABO mating types.

Altogether the ABO groups of the mothers and fathers of 2,100 matings are available. Only one child of each mating has had a blood group determination, but the sex of 3,791 children born of these matings is known. The full details are given in Table III, the mating types having been arranged in descending order according to sex ratio. The numbers of some of the rarer mating types are too small for comparison, but are given for the sake of completeness.

Again the difference between the sex ratios of children born to Group B mothers and fathers is apparent. In the case of the children of Group B mothers, the sex ratio for each mating is well above 50 per cent., and for those with Group B fathers it is less than 50 per cent., excepting the mating $\mathbf{B} \times \mathbf{B}$. Excluding this mating, the average sex ratio for each mating with a mother of Group B $(\mathrm{O} \times \mathrm{B} ; \mathrm{A} \times \mathrm{B} ; \mathrm{AB} \times \mathrm{B})$ is $55.4 \pm 2 \cdot 9$, and that for matings with Group $\mathbf{B}$ fathers $(\mathbf{B} \times \mathbf{O} ; \mathbf{B} \times \mathbf{A} ; \mathbf{B} \times \mathbf{A B})$ is $47 \cdot 5 \pm 2 \cdot 7$. The difference between the two ratios falls only just outside the 0.05 level of probability $\left(\chi^{2}=3 \cdot 799\right)$.

Allan (1952b, 1953), reviewing the data of Waterhouse and Hogben (1947) and of Sanghvi (1951), noted differences in fertility associated with both sex and blood group. Disregarding matings in which both partners were of the same group, for fathers the descending order of fertility was $B-A B-O-A$, while the reverse (A - O - AB - B) was true for mothers, irrespective of whether the matings were homospecific or heterospecific. These differences were not observed in this sample, no definite fertility order being apparent for either mother or father (Table III, column 8).
TABLE III

FERTILITY AND SEX RATIO DATA OF VARIOUS MATING TYPES

\begin{tabular}{|c|c|c|c|c|c|c|c|}
\hline \multicolumn{2}{|c|}{$\begin{array}{c}\text { Parents' Blood } \\
\text { Group }\end{array}$} & \multirow{2}{*}{$\begin{array}{l}\text { Num- } \\
\text { ber of } \\
\text { Matings }\end{array}$} & \multirow{2}{*}{$\begin{array}{l}\text { Num- } \\
\text { ber of } \\
\text { Chil- } \\
\text { dren }\end{array}$} & \multicolumn{2}{|c|}{$\begin{array}{l}\text { Sex of } \\
\text { Children }\end{array}$} & \multirow{2}{*}{$\begin{array}{l}\text { Per } \\
\text { cent. } \\
\text { Male }\end{array}$} & \multirow{2}{*}{ Fertility } \\
\hline Father & Mother & & & Male & Female & & \\
\hline $\mathbf{A B}$ & B & 8 & 11 & 8 & 3 & $72 \cdot 7$ & $1 \cdot 37$ \\
\hline $\mathbf{A B}$ & 0 & 26 & 54 & 39 & 15 & $72 \cdot 2$ & $2 \cdot 08$ \\
\hline B & B & 16 & 25 & 15 & 10 & $\overline{60} \cdot \overline{0}$ & 1.56 \\
\hline O & B & 71 & 133 & 74 & 59 & $55 \cdot 6$ & 1.87 \\
\hline $\mathbf{A}$ & B & 75 & 136 & 73 & 63 & $53 \cdot 7$ & $1 \cdot 81$ \\
\hline 0 & AB & 24 & 52 & 27 & 25 & $51 \cdot 9$ & $2 \cdot 17$ \\
\hline 0 & 0 & 446 & 799 & 412 & 387 & $51 \cdot 6$ & $1 \cdot 79$ \\
\hline $\mathbf{A}$ & O & 401 & 693 & 353 & 340 & $50 \cdot 9$ & 1.73 \\
\hline 0 & $\mathbf{A}$ & 386 & 701 & 351 & 350 & $50 \cdot 1$ & 1.82 \\
\hline $\mathbf{A}$ & $\mathbf{A}$ & 402 & 741 & 370 & 371 & $49 \cdot 9$ & $1 \cdot 84$ \\
\hline B & 0 & 95 & 167 & 81 & 86 & $48 \cdot 5$ & $1 \cdot 76$ \\
\hline $\mathbf{A B}$ & $\mathbf{A}$ & 27 & 43 & 20 & 23 & $46 \cdot 5$ & 1.59 \\
\hline B & A & 84 & 157 & 73 & 84 & $46 \cdot 5$ & $1 \cdot 87$ \\
\hline B & $\mathbf{A B}$ & 8 & 13 & 6 & 7 & $46 \cdot 2$ & $1 \cdot 62$ \\
\hline $\mathbf{A}$ & AB & 29 & 63 & 28 & 35 & $44 \cdot 4$ & $2 \cdot 17$ \\
\hline$\overline{A B}$ & AB & 2 & 3 & 1 & 2 & $33 \cdot 3$ & 1.50 \\
\hline Total & $\ldots$ & 2,100 & 3,791 & 1,931 & 1,860 & $50 \cdot 9$ & 1.81 \\
\hline
\end{tabular}

\section{Discussion}

The reason for the difference in the sex ratios of live births is not fully understood, and it has been explained by postulating differential conception rates. Theoretically equal numbers of $X$ - and $Y$-bearing spermatozoa should be produced, but a hypothetical system whereby a certain limit of deviation might occur has been described by Novitski $(1951,1953)$.

More readily determined is the effect of abortions and stillbirths on the sex ratio of live births. It has been shown by Ciocco (1938a), Lowe and McKeown (1950), and McKeown and Lowe (1951), that the sex ratio of foetus lost by abortions and stillbirths varies according to the period of gestation and also depends to some extent on the various causes and conditions. This may explain some of the variations in the sex ratio of live births seen under certain conditions and avoids any need to postulate any differential conception rate.

It has been held that serological factors may influence the numbers of children of each blood 
group born to various mating types, and Hirszfeld (1928) and later Waterhouse and Hogben (1947) claimed there to be a deficiency of Group A children born of the heterospecific $\mathrm{A} \times \mathrm{O}$ matings. This was not substantiated by Hirszfeld in a second paper (1934), nor in an analysis of the population from which this sample is taken (Johnstone, 1954). In Table III the descending order of sex ratio is seen to bear no relationship to the type of mating (i.e. whether homospecific or heterospecific).

An association is recognized between birth rank and sex ratio, the ratio being highest in the first rank and steadily falling thereafter to the fourth or fifth rank. Further, sex ratio is not correlated with maternal age except inasmuch as with increasing maternal age the likelihood of further pregnancies is increased; any relationship which may exist between the age of the parents and the sex ratio appears to be associated with the age of the father (Russell 1936; Ciocco 1938b; Martin 1948; Lowe and McKeown 1950; Novitski 1953; MacMahon and Pugh 1953). In Table IV the sex ratio for each birth rank is given for the matings in which either the father or mother is of Group B in the present sample. In the first rank the low ratio for children of Group B fathers and the high ratio for children of Group B mothers are obvious. The difference is highly significant $\left(\chi^{2}=8.43 ; .01>P>.001\right)$; in the other ranks the differences are not significant, but here the numbers of children are much smaller. Occurring as it does in the first rank, this difference is most unlikely to be due to any serological cause, especially as it is not repeated in the other ranks. In this connection it is interesting that Allan (1953) has found in the family data compiled by Waterhouse and Hogben (1947) that fathers of Group B have the highest fertility while mothers of Group B have the lowest fertility.
While the sex ratios differ between children of Group B mothers and fathers, in the whole sample the differences between the reciprocal matings tend to cancel out one another, the mean percentage of males in the matings $\mathrm{O} \times \mathrm{B}$ and $\mathrm{B} \times \mathrm{O}(1.06)$ and $A \times B$ and $B \times A(0.99)$ being close to those in other matings, such as the mean of $O \times A$ and $A \times O(1.02), O \times O(1.06)$, and $A \times A(0.99)$.

It is most probable therefore, that although there is a considerable difference between the sex ratios of children born to Group B mothers and fathers, particularly in the first rank, this difference is unlikely to affect to any extent the proportion of male children born to any population, or the number of Group B persons from one generation to another.

\section{SUMmary}

(1) A West London population has been examined for any association between the ABO blood group system and the sex ratio.

(2) In heterozygous matings more male children are born to Group B mothers than to the wives of Group B fathers. The difference is significant in the first birth rank.

(3) It is suggested that this difference will have no effect on the proportion of male children born to any given population, or on the number of persons of Group B in that population over several generations.

(4) The finding of Sanghvi (1951) that the sex ratio of Group $\mathbf{O}$ infants born to Group $\mathbf{O}$ mothers is significantly higher than that of Group $A$ infants born to Group A mothers has not been confirmed.

I am indebted to Mr. D. M. Stern for allowing me access to the clinical material, and to the medical and nursing staff of his department for their co-operation, and also to Dr. P. L. McKinlay who kindly read the manuscript.

TABLE IV

SEX RATIOS BY BIRTH RANK FOR MATINGS IN WHICH EITHER THE FATHER OR MOTHER IS OF GROUP B, IRRESPECTIVE OF THE GROUP OF THE CHILD

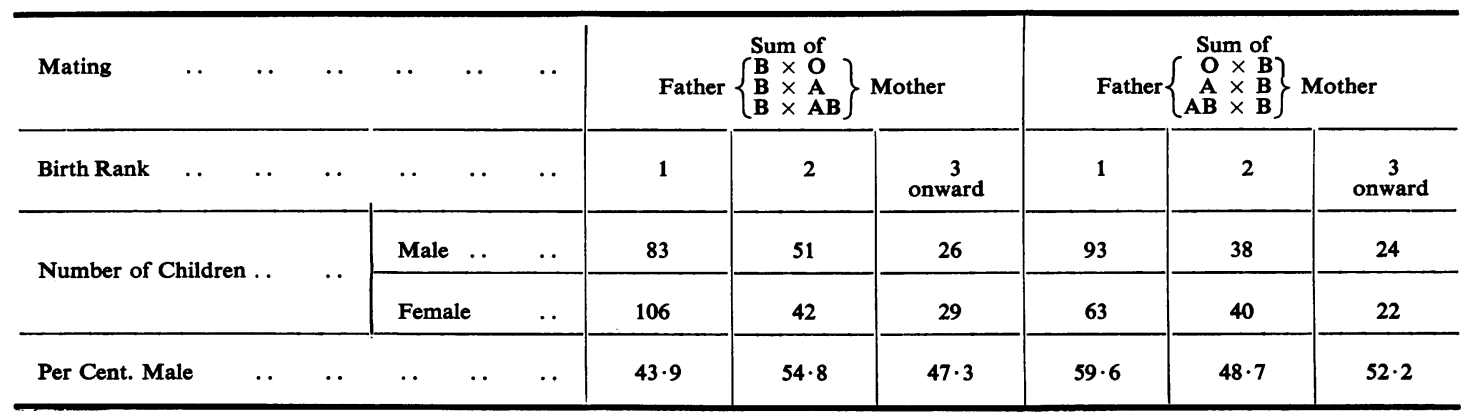




\section{REFERENCES}

Allan, T. M. (1952a). Lancet, 1, 102. (1952b). Ibid., 1, 370.

(1953). British Journal of Social Medicine, 7, 220.

Ciocco, A. (1938a). Hum. Biol., 10, 235.

(1938b). Ibid., 10, 36.

Hirszfeld, L. (1928). "Konstitutionsserologie und Blutgruppenforschung". Springer, Berlin.

(1934). Ergebn. Hyg. Bakt., 15, 54.

Johnstone, J. M. (1954). British Journal of Preventive and Social Medicine, 8, 117.

Lowe, C. R., and McKeown, T. (1950). British Journal of Social Medicine, 4, 75 .
MacMahon, B., and Pugh, T. F. (1953). Ibid., 7, 83.

Martin, W. J. (1948). Med. Offr, 79, 153.

McKeown, T., and Lowe, C. R. (1951). Hum. Biol., 23, 41.

Medical Research Council (1943). "The Determination of Blood Groups". War Memorandum, No. 9. H.M.S.O., London.

Mollison, P. L., Mourant, A. E., and Race, R. R. (1948). "The Rh Blood Groups". Med. Res. Coun. Mem. No. 19. H.M.S.O., London.

Novitski, E. (1951). Genetics, 36, 267. (1953). Science, 117, 531.

Russell, W. T. (1936). J. Hyg. (Lond.), 36, 381.

Sanghvi, L. D. (1951). Nature (Lond.), 168, 1077.

Waterhouse, J. A. H., and Hogben, L. (1947). British Journal of Social Medicine, 1, 1 . 